Check for updates

Cite this: RSC Adv., 2018, 8, 24422

\title{
A systematic study of the co-solvent effect for an all-organic redox flow battery
}

\author{
Xiang Wang, ${ }^{\text {ab }}$ Xueqi Xing, ${ }^{\text {ab }}$ Yongjie Huo, ${ }^{\text {ab }}$ Yicheng Zhao (D) *ab and Yongdan Li ${ }^{\star a b c}$ \\ Benzophenone and 1,4-di-tert-butyl-2,5-dimethoxybenzene are used as the anode and cathode active species \\ respectively in an all-organic redox-flow battery. A number of organics as the co-solvents are applied in the \\ electrolyte to improve the electrochemical performance of it. For all kinds of the mixed solvents, a lower \\ content of acetonitrile leads to a higher solubility to 1,4-di-tert-butyl-2,5-dimethoxybenzene and a lower \\ conductivity. The results of cyclic voltammetry tests demonstrate that the electrode reactions are controlled \\ by diffusion. With the decrease of the content of acetonitrile, the dynamic viscosity of the electrolyte \\ increases, which generally leads to the decrease of the diffusion coefficients of the active species.
}

Received 22nd March 2018 Accepted 29th June 2018

DOI: $10.1039 / c 8 \mathrm{ra02513d}$

rsc.li/rsc-advances
NARFB using BP as the anode species to provide a low anode potential was realized by Xing et al. ${ }^{19} \mathrm{~A}$ number of redox active species based on the general structure of dimethoxy-di-tertbutylbenzene as the cathode active molecule for NARFBs were reported by Huang et al. ${ }^{20,21}$ With a similar structure, 1,4-di-tertbutyl-2,5-dimethoxybenzene (DBB) was proposed as a stable redox shuttle with a high cathode potential. ${ }^{22,23}$ However, it has not been used in NARFBs due to its low solubility in polar electrolyte solutions.

The effects of solvents and supporting electrolytes in electrochemical reactions have been investigated extensively. Nonaqueous electrolytes are often flammable, volatile and moisture-sensitive. Furthermore, the cost and ionic conductivities are far less competitive compared to their aqueous counterparts. Creager ${ }^{24}$ postulated that for the electrolytes of batteries, polar solvents are beneficial to achieve a reasonable ionic conductivity. In addition to the polarity, the solubilities of active species and supporting electrolytes, which influence the kinetics of the electrode reactions and the energy density of the battery, are also crucial for the selection of solvents. Shinkle et al. ${ }^{25}$ presented an approach to promote the cell efficiency through monitoring the property of the organic solvent. They found that the solubility of the active species vanadium acetylacetonate $\left(\mathrm{V}(\mathrm{acac})_{3}\right)$ and the ionic conductivity of the electrolyte increase with the rise of the polarity, Hildebrand solubility and molar volume of the solvent. Herr et al. ${ }^{26,27}$ found that in a nonaqueous vanadium RFB, the vibrational bond energy of the solvent would be changed by the addition of a co-solvent, resulting in the variation of the solubility of the active species. Bamgbopa et al. ${ }^{28}$ reported that the solvents affected the physical and electrochemical properties of the electrolytes and hence influenced the reaction kinetics of the non-aqueous vanadium RFB.

In this work, BP and DBB are used as the anode and cathode active species, respectively. Acetonitrile (AN) is employed as the 
Table 1 Physical properties of the organic solvents used in this work

\begin{tabular}{|c|c|c|c|c|}
\hline Pure solvent & Dielectric constant ${ }^{a}$ & Dynamic viscosity $^{a}$ (mPa s) & Solubility of BP $\left(\mathrm{mol} \mathrm{L}^{-1}\right)$ & Solubility of DBB $\left(\mathrm{mol} \mathrm{L}^{-1}\right)$ \\
\hline AN & 35.95 & 0.34 & 13.16 & 0.17 \\
\hline DMC & 3.11 & 0.58 & 11.40 & 0.58 \\
\hline $\mathrm{DMF}$ & 36.71 & 0.80 & 11.10 & 0.41 \\
\hline DOL & 6.98 & 0.59 & 13.30 & 0.96 \\
\hline GBL & 39.10 & 1.73 & 11.80 & 0.15 \\
\hline
\end{tabular}

${ }^{a}$ Obtained from ref. 32 .

main solvent. Five common organics are used as co-solvents. The effects of the co-solvents on the properties of the electrolyte and the electrode reactions are investigated.

\section{Experimental}

\subsection{Materials preparation}

The co-solvents, dimethyl carbonate (DMC, 99\%, MACKLIN, China), diethyl carbonate (DEC, 99\%, MACKLIN, China), gamma-butyrolactone (GBL, 99\%, MACKLIN, China), dimethyl formamide (DMF, 99\%, Guangfu, China) and 1,3-dioxolane (DOL, 99.5\%, Energy, China) were dried with 4A molecular sieve (Guangfu, China) for $48 \mathrm{~h}$ before used. The solvent AN (99\%, MACKLIN, China) was distilled with the presence of calcium hydride under nitrogen. The active species DBB (98\%, Bide, China) and BP (98\%, Guangfu, China) were used without any pretreatment.

The supporting electrolyte tetraethylammonium hexafluorophosphate $\left(\mathrm{TEAPF}_{6}\right)$ was synthesized with a two-step procedure. $^{29}$ Tetraethylammonium bromide (TEABr) was firstly prepared with the reaction of pure triethylamine and ethyl bromide at $55{ }^{\circ} \mathrm{C}$ for $24 \mathrm{~h}$. After being washed with THF and filtered, the solid TEABr was dried in vacuum at $80^{\circ} \mathrm{C}$ for $48 \mathrm{~h}$. Then the TEABr and potassium hexafluorophosphate were dissolved in deionized water and stirred at $50{ }^{\circ} \mathrm{C}$ for $20 \mathrm{~h}$ to get the $\mathrm{TEAPF}_{6}$ crystallites. The product was rinsed with deionized water and dried in vacuum at $60{ }^{\circ} \mathrm{C}$ for $24 \mathrm{~h}$.

\subsection{Characterization}

The solubilities of BP and DBB in different solvents were measured by weighing solute and gradually dissolving in the quantitative solvent or solvent mixture $(0.5$ or $1.0 \mathrm{~mL})$ with vigorous shaking. At overnight intervals, more solute (in 0.0005 or $0.0010 \mathrm{~g}$ increments) was added until precipitation occurred. With this method, a precision of $1 \mathrm{~g} \mathrm{~L}^{-1}$ can be reached. ${ }^{30}$ The conductivities of the mixed solvents with $0.01 \mathrm{M} \mathrm{TEAPF}_{6}$ were measured with a DDS-307A conductivity meter (REX, China) with a DJS-1C platinum black electrode (REX, China) at $25{ }^{\circ} \mathrm{C}$. The measurements were repeated for three times to get the average value.

\subsection{Cyclic voltammetry tests}

CV measurements were carried out with an electrochemical workstation (VersaSTAT 3, Ametek) at $25{ }^{\circ} \mathrm{C}$. A three-electrode electrochemical cell was assembled. A glassy-carbon disk with a diameter of $6 \mathrm{~mm}$ (Aidahengsheng, China) was used as the working electrode. The reference electrode was $\mathrm{Ag} / \mathrm{Ag}^{+}$electrode (0.5 $\mathrm{M} \mathrm{AgNO}_{3}$ in AN, Aidahengsheng, China). A graphite plate with a geometry surface area of $5.24 \mathrm{~cm}^{2}$ (Aidahengsheng, China) was adopted as the counter electrode. Prior to the measurement, the glassy-carbon electrode was polished with chamois leather and alumina powder $0.05 \mu \mathrm{m}$, Aidahengsheng,

(a)

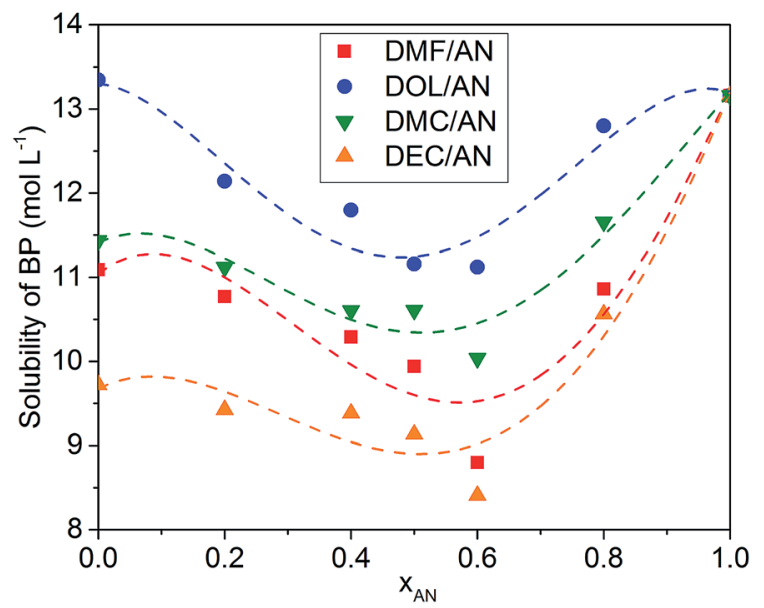

(b)

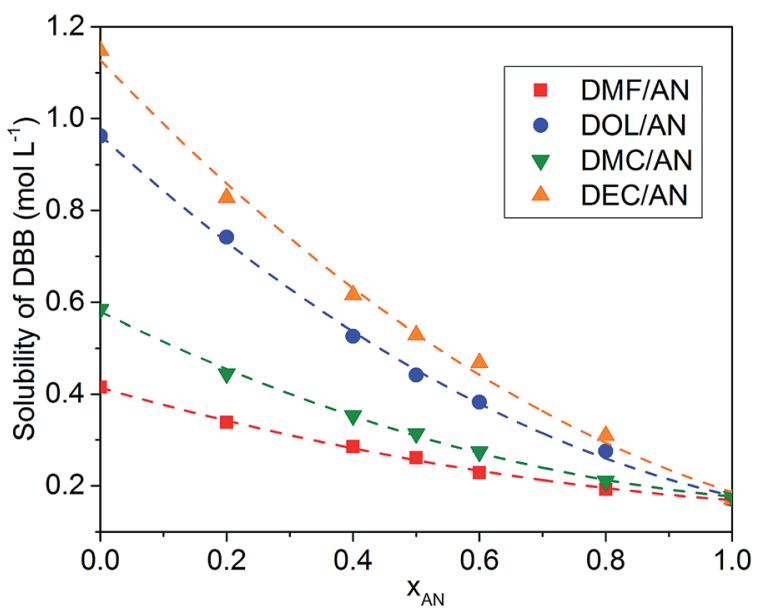

Fig. 1 Solubilities of (a) BP and (b) DBB in the mixed solvents. 
Table 2 The regression constants $\left(\ln \left(\mathrm{mol} \mathrm{L}^{-1}\right)\right)$ in the Jouyban-Acree model to fit the solubility of BP in the mixed solvents

\begin{tabular}{llllll}
\hline Mixed solvents & $A_{0}$ & $A_{1}$ & $A_{2}$ & $A_{3}$ & $A_{4}$ \\
\hline DMF/AN & 2.41 & 2.59 & 2.27 & 2.44 & 2.41 \\
DOL/AN & 2.38 & 2.50 & 2.24 & 2.41 & 2.38 \\
DMC/AN & 2.30 & 2.41 & 2.21 & 2.36 & 2.30 \\
DEC/AN & 2.33 & 2.47 & 2.24 & 2.36 & 2.33
\end{tabular}

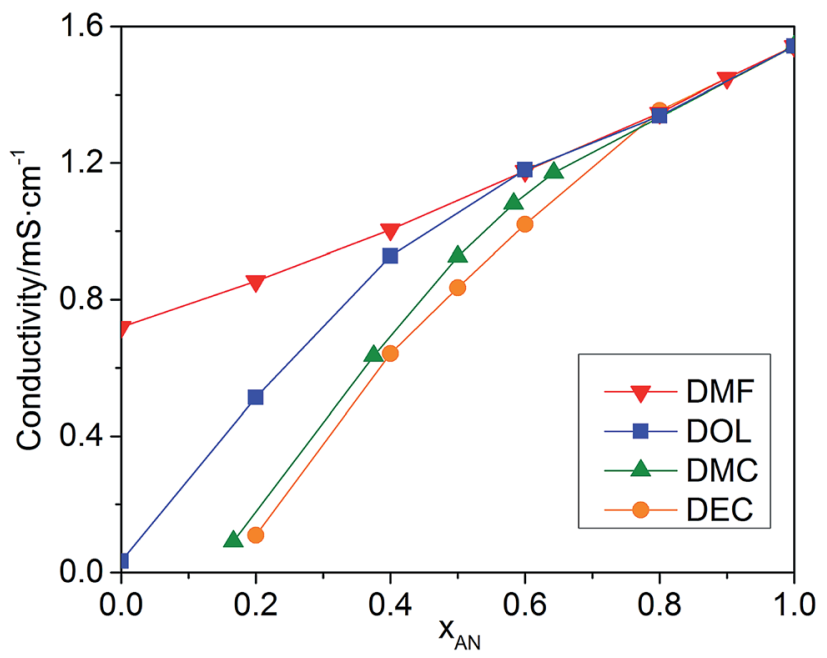

Fig. 2 Conductivities of the mixed solvents with various $x_{\mathrm{AN}}$ and $0.01 \mathrm{M} \mathrm{TEAPF}_{6}$.

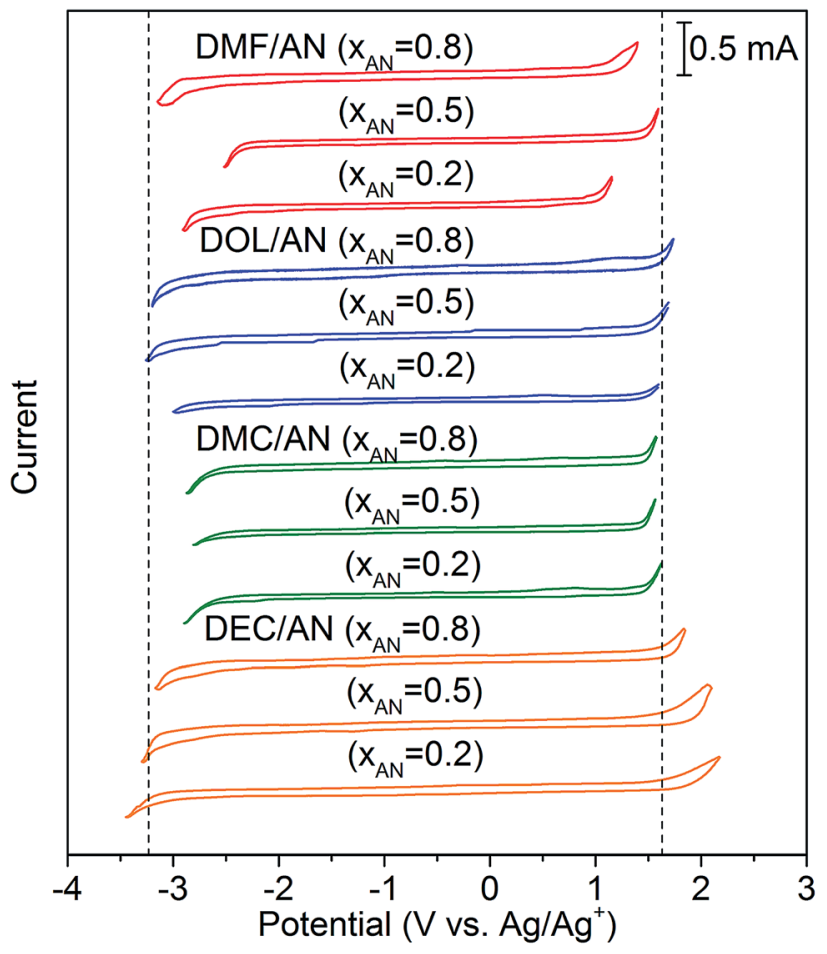

Fig. 3 Cyclic voltammograms of the mixed solvents with 0.1 M TEAPF 6 at the scanning rate of $0.5 \mathrm{~V} \mathrm{~s}^{-1}$. The ESW of pure AN measured in the same condition is shown as the dotted lines.
China). After being polished, the electrode was ultrasonically cleaned with deionized water and dried at $80{ }^{\circ} \mathrm{C}$ for $24 \mathrm{~h}$. The electrolyte, which contained 0.01 M BP, 0.01 M DBB and 0.1 M $\mathrm{TEAPF}_{6}$, was deoxygenated with nitrogen (99.999\% pure, Liufang, China) for $10 \mathrm{~min}$ prior to all the measurements. The CV curves were recorded in the potential range from -2.6 to $1.2 \mathrm{~V}$ $\left(v s . \mathrm{Ag} / \mathrm{Ag}^{+}\right)$at various scanning rates between 0.07 and $0.6 \mathrm{~V} \mathrm{~s}^{-1}$. The diffusion coefficients of the redox species in the electrolytes were estimated based on the Randles-Sevcik equation without IR drop compensation. ${ }^{31}$ For a reversible electron transfer reaction:

$$
i_{\mathrm{p}}=2.69 \times 10^{5} n^{3 / 2} A c D^{1 / 2} \nu^{1 / 2}
$$

For an irreversible electron transfer reaction:

$$
i_{\mathrm{p}}=2.99 \times 10^{5} n^{3 / 2} \alpha^{1 / 2} A c D^{1 / 2} \nu^{1 / 2}
$$

where $i_{\mathrm{p}}$ is the peak current (A), $n$ the number of electrons transferred in the redox reaction process $(n=1), \alpha$ the

(a)

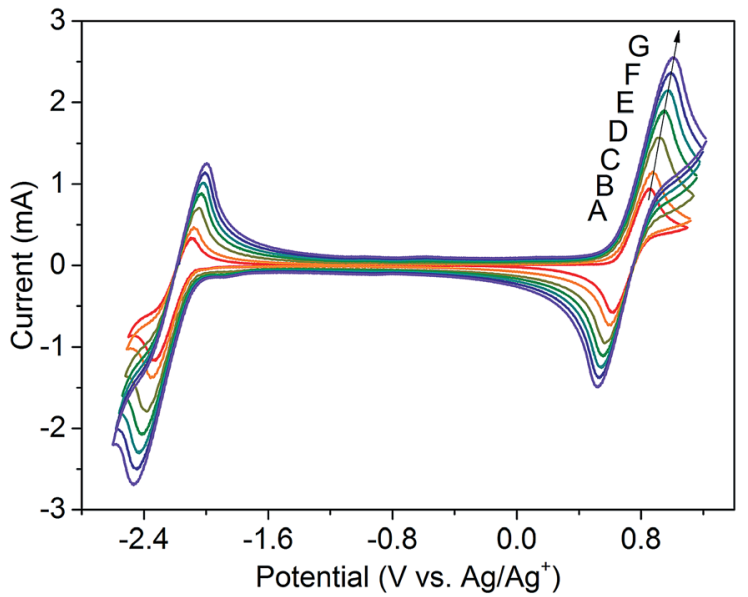

(b)

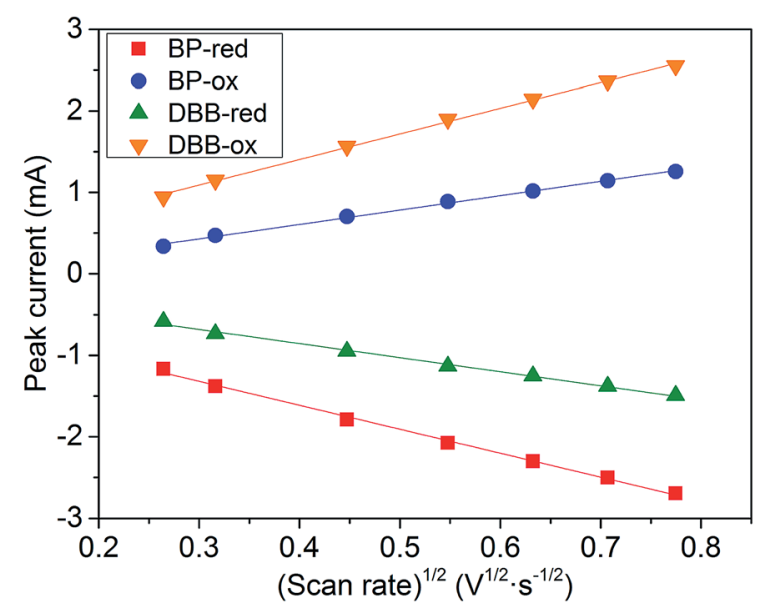

Fig. 4 (a) Cyclic voltammograms of BP and DBB in DOL/AN ( $\left.x_{\mathrm{AN}}=0.5\right)$ with various scanning rates: (A) $0.07 \mathrm{~V} \mathrm{~s}^{-1}$, (B) $0.1 \mathrm{~V} \mathrm{~s}^{-1}$, (C) $0.2 \mathrm{~V} \mathrm{~s}^{-1}$, (D) $0.3 \mathrm{Vs}^{-1}$, (E) $0.4 \mathrm{~V} \mathrm{~s}^{-1}$, (F) $0.5 \mathrm{~V} \mathrm{~s}^{-1}$ and (G) $0.6 \mathrm{~V} \mathrm{~s}^{-1}$. (b) The relationship between the peak currents of the electrode reactions and the scanning rate. 
transfer coefficient $(\alpha=0.5), A$ the electrode area $\left(0.28 \mathrm{~cm}^{2}\right)$, $c$ the primary redox species concentration (M), $\nu$ the scanning rate $\left(\mathrm{V} \mathrm{s}^{-1}\right)$ and $D$ the diffusion coefficient $\left(\mathrm{cm}^{2} \mathrm{~s}^{-1}\right)$. Generally, every CV curve need more than 5 circles to avoid error points.

\section{Results and discussion}

The solubilities of BP and DBB in various solvents are listed in Table 1. Table 1 also presents the physical and chemical properties of the solvents obtained from ref. 32 . The solubilities of BP in all of the solvents are higher than those of DBB. AN possesses a low solubility to DBB of about $0.17 \mathrm{~mol} \mathrm{~L}^{-1}$, while most of the co-solvents used in this work show a higher solubility to DBB except GBL. Generally, the solvent with a lower dielectric constant exhibits a weaker polarity, resulting in a stronger ability to dissolve low-polar molecules such as DBB. However, DMF is an exception with a high dielectric constant and a high solubility to DBB compared with those of AN. Meanwhile, AN possesses the lowest dynamic viscosity in all of the solvents.

The solubilities of BP in the binary mixed solvents with the same volume content of AN $\left(x_{\mathrm{AN}}\right)$ show an order of DOL/AN > DMC/AN > DMF/AN > DEC/AN (Fig. 1a), which is consistent with the order of the solubilities of BP in the corresponding pure cosolvents. For all of the mixed solvents, the lowest solubility of $\mathrm{BP}$ is obtained when $x_{\mathrm{AN}}$ is 0.6. The relationship between the solubility of BP and $x_{\mathrm{AN}}$ fits the Jouyban-Acree model, which was firstly used to calculate the viscosity of binary solvents. ${ }^{33}$ This model has also been applied to describe the solubility of $\mathrm{V}(\mathrm{acac})_{3}$ in binary solvents. ${ }^{28}$ In this work, the model is expressed as:

$$
\ln S=A_{0}+A_{1} x_{\mathrm{AN}}+A_{2} x_{\mathrm{AN}}^{2}+A_{3} x_{\mathrm{AN}}^{3}+A_{4} x_{\mathrm{AN}}^{4}
$$

where $S$ is the solubility of BP $\left(\mathrm{mol} \mathrm{L}^{-1}\right) . A_{0}, A_{1}, A_{2}, A_{3}$ and $A_{4}$ are regression constants $\left(\ln \left(\mathrm{mol} \mathrm{L}^{-1}\right)\right)$, which are listed in Table 2 . Fig. $1 \mathrm{~b}$ shows the solubilities of DBB in the mixed solvents, which show an order of DEC/AN $>$ DOL/AN $>$ DMC/AN $>$ DMF/ $\mathrm{AN}$, in accordance with the order of the solubilities of $\mathrm{DBB}$ in the pure co-solvents. The solubilities of $\mathrm{BP}$ in the mixed solvents are much higher than those of DBB. Therefore, the energy capacity of the NARFBs is mainly determined by the solubility of DBB in the solvent. With the decrease of $x_{\mathrm{AN}}$, the solubility of DBB in all of the solvents increases, which would improve the energy capacity of the corresponding battery.

The conductivities of the mixed solvents with $0.01 \mathrm{M} \mathrm{TEAPF}_{6}$ and various $x_{\mathrm{AN}}$ are plotted in Fig. 2. Pure AN presents the highest conductivity. For all of the mixed solvents, the conductivity decreases with the decrease of $x_{\mathrm{AN}}$. When $x_{\mathrm{AN}}$ is 0.8 , the conductivities of the mixed solvents are almost the same. When $x_{\mathrm{AN}}$ is lower than 0.5, the conductivities of the mixtures show an order of DMF/AN > DOL/AN > DMC/AN > DEC/AN. The electrochemical stability windows (ESWs) of the mixed solvents with $0.1 \mathrm{M} \mathrm{TEAPF}_{6}$ are shown in Fig. 3. The ESW of pure AN is -3.25 to $1.64 \mathrm{~V}\left(v s . \mathrm{Ag} / \mathrm{Ag}^{+}\right)$. The addition of DMC and DMF narrows the ESW of AN, while DOL/AN exhibit a comparable ESW to AN, which widens with the increase of $x_{\mathrm{AN}}$. DEC/AN shows the widest ESW of over $5.0 \mathrm{~V}$ when $x_{\mathrm{AN}}$ is lower than 0.5.

\section{The redox reactions at the anode}<smiles>O=C(c1ccccc1)c1ccccc1</smiles>

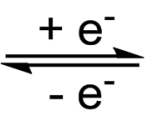<smiles>[O-]C(c1ccccc1)c1ccccc1</smiles>

\section{The redox reactions at the cathode}
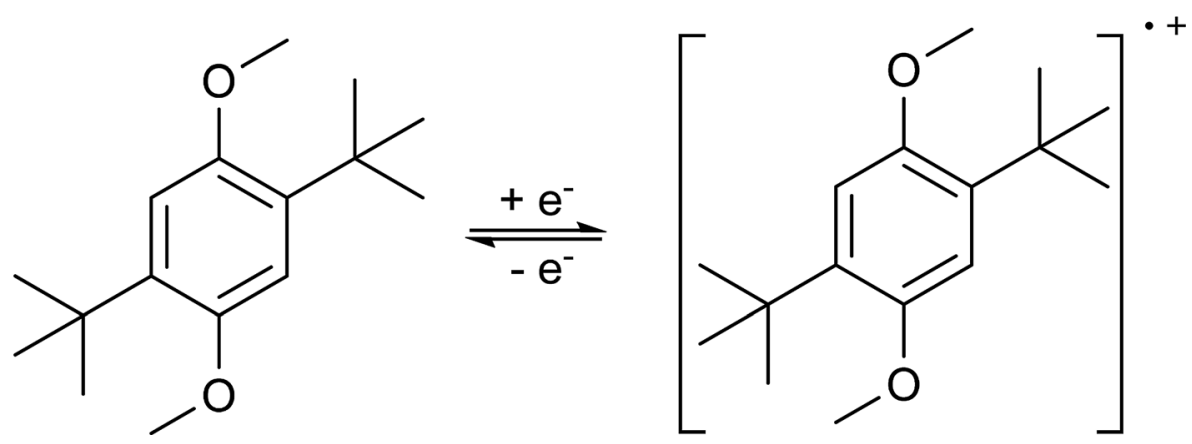

Scheme 1 The redox reactions of BP and DBB at the anode and cathode sides. 
$\mathrm{CV}$ results of $\mathrm{BP}$ and $\mathrm{DBB}$ with a concentration of $0.01 \mathrm{M}$ in the $\mathrm{DOL} / \mathrm{AN}\left(x_{\mathrm{AN}}=0.5\right)$ mixture with various scanning rates are presented in Fig. 4a. The redox reactions of the active species are illustrated in Scheme 1. Only the peaks corresponding to $\mathrm{BP}^{-} / \mathrm{BP}$ and $\mathrm{DBB} / \mathrm{DBB}^{+}$redox couples are observed in the potential range from -2.6 to $1.2 \mathrm{~V}\left(v s . \mathrm{Ag} / \mathrm{Ag}^{+}\right)$within the ESW of the mixed solvent. When the scanning rate is $0.07 \mathrm{~V} \mathrm{~s}^{-1}$, the oxidation and reduction peaks of BP appear at -2.09 and $-2.33 \mathrm{~V}\left(v s . \mathrm{Ag} / \mathrm{Ag}^{+}\right)$, while those of DBB are at 0.86 and $0.62 \mathrm{~V}$ $\left(v s . \mathrm{Ag} / \mathrm{Ag}^{+}\right)$, respectively. With the increase of the scanning rate, the oxidation peaks move to a higher potential, while the reduction peaks shift to a lower potential. At the scanning rate of $0.5 \mathrm{~V} \mathrm{~s}^{-1}$, the peak separation between the oxidation and reduction processes of $\mathrm{BP}$ and $\mathrm{DBB}$ are 0.44 and $0.46 \mathrm{~V}$, respectively, and the half-wave potentials are -2.23 and $0.76 \mathrm{~V}$ (vs. $\mathrm{Ag} / \mathrm{Ag}^{+}$) respectively, yielding a wide theoretical cell potential of $2.99 \mathrm{~V}$. For both $\mathrm{BP}$ and $\mathrm{DBB}$, the values of the peak current ratios $\left(i_{\text {p.a }} / i_{\text {p.c }}\right)$ are close to 1 , which indicates a quasireversible behavior for both $\mathrm{BP}^{-} / \mathrm{BP}$ and $\mathrm{DBB} / \mathrm{DBB}^{+}$couples. The linear relationship between the peak currents of the electrode reactions and the square root of the scanning rate (Fig. 4b) indicates that all the reactions are controlled by diffusion. ${ }^{31}$ The diffusion coefficients are calculated based on eqn (1) and (2), which are in the ranges of 1.53-1.98 $\times 10^{-5}$ and 1.75-2.53 $\times$ $10^{-5} \mathrm{~cm}^{2} \mathrm{~s}^{-1}$ for BP and DBB, respectively.

The diffusion coefficients of the electrode reactions calculated by eqn (1), in which the reactions are considered as reversible reactions, are presented in Fig. 5. For DEC/AN and DMC/AN, CV curves are not obtained when $x_{\mathrm{AN}}$ is lower than 0.5 due to the low conductivity of the solvent. In all of the solvents, the diffusion coefficients of the cathode reduction and anode oxidation reactions are higher than those of the anode reduction and cathode oxidation reactions. The diffusion coefficients of the reactions generally increase with the increase of $x_{\mathrm{AN}}$ with a few exceptions. Meanwhile, the viscosities of the mixed solvents, which are calculated based on the viscosity data of the pure solvents listed in Table 1 and the Jouyban-Acree model, ${ }^{33}$ are also shown in Fig. 5. As AN has the lowest dynamic viscosity, the dynamic

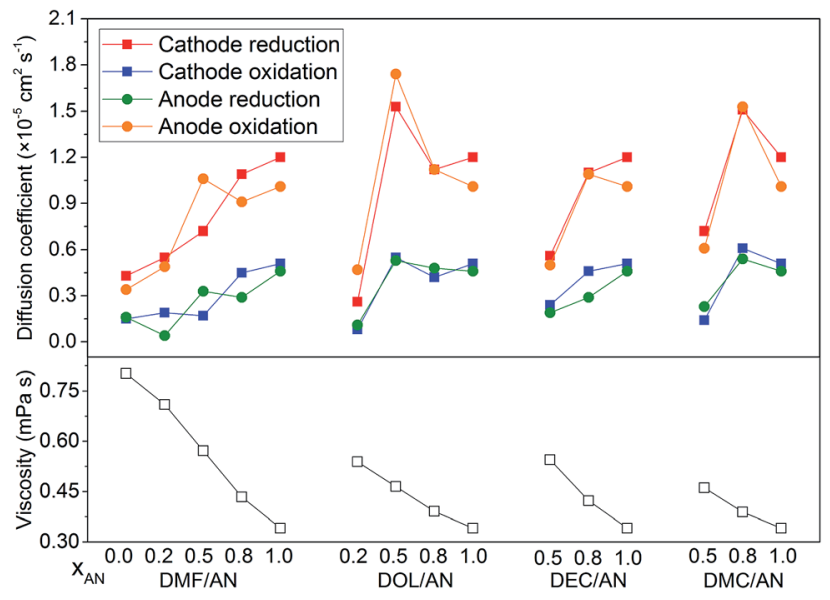

Fig. 5 The viscosities of the mixed solvents with different contents and the diffusion coefficients of the electrode reactions in various solvents. viscosity of the mixed solvents rises with the reduced concentration of $x_{\mathrm{AN}}$. Since all of the electrode reactions are diffusion controlled, the increase of the viscosity of the electrolyte with the decrease of $x_{\mathrm{AN}}$, which is the probable reason for the decrease of the diffusion coefficients of the reactions, would lead to slower electrode kinetics. However, further investigation is still needed to explain the exceptions to this tendency as observed when DOL/ $\mathrm{AN}\left(x_{\mathrm{AN}}=0.5\right)$ and DMC/AN $\left(x_{\mathrm{AN}}=0.8\right)$ are used as the solvents.

\section{Conclusions}

In this work, we have presented a systematic approach to screen and optimize organic solvent mixtures to improve the electrochemical performance of all-organic RFBs. DMC, DEC, DMF, DOL and GBL are investigated as the co-solvents in an allorganic redox flow battery with $\mathrm{AN}$ as the solvent and $\mathrm{BP}$ and DBB as the active species. The solubilities of BP in the mixed solvents are much higher than those of DBB. With the decrease of $x_{\mathrm{AN}}$ in the electrolyte, the solubility of DBB increases, while the conductivity of the electrolyte decreases. The potentials of $\mathrm{BP}^{-} / \mathrm{BP}$ and $\mathrm{DBB} / \mathrm{DBB}^{+}$redox couples are within the ESWs of the mixed solvents. The electrode reactions are controlled by diffusion. The diffusion coefficients of the reactions tend to increase with the decrease of $x_{\mathrm{AN}}$ in the electrolyte, which is probably due to the increase of the viscosity of the solvent.

\section{Conflicts of interest}

There are no conflicts to declare.

\section{Acknowledgements}

The financial support of NSF of China under contract numbers 21636007 and 51402210 and the support of Tianjin Municipal Science and Technology Commission under contract numbers 15JCQNJC06500 are gratefully acknowledged. The work has been also supported by the Program of Introducing Talents to the University Disciplines under file number B06006, and the Program for Changjiang Scholars and Innovative Research Teams in Universities under file number IRT 0641.

\section{References}

1 L. H. Thaller, Presented in part at the Proc. 9th Intersoc. Energy Conv. Eng. Conf., San Francisco, CA, 26-30, August, 1974.

2 A. Z. Weber, M. M. Mench, J. P. Meyers, P. N. Ross, J. T. Gostick and Q. Liu, J. Appl. Electrochem., 2011, 41, 1137-1164.

3 G. L. Soloveichik, Chem. Rev., 2015, 115, 11533-11558.

4 S. Hameer and J. L. van Niekerk, Int. J. Energy Res., 2015, 39, 1179-1195.

5 B. R. Chalamala, T. Soundappan, G. R. Fisher, M. R. Anstey, V. V. Viswanathan and M. L. Perry, Proc. IEEE, 2014, 102, 976999.

6 P. Leung, A. A. Shah, L. Sanz, C. Flox, J. R. Morante, Q. Xu, M. R. Mohamed, C. Ponce de León and F. C. Walsh, J. Power Sources, 2017, 360, 243-283. 
7 M. Skyllas-Kazacos, M. H. Chakrabarti, S. A. Hajimolana, F. S. Mjalli and M. Saleem, J. Electrochem. Soc., 2011, 158, R55.

8 J. Noack, N. Roznyatovskaya, T. Herr and P. Fischer, Angew. Chem., Int. Ed. Engl., 2015, 54, 9776-9809.

9 X. Wei, W. Xu, J. Huang, L. Zhang, E. Walter, C. Lawrence, M. Vijayakumar, W. A. Henderson, T. Liu, L. Cosimbescu, B. Li, V. Sprenkle and W. Wang, Angew. Chem., Int. Ed. Engl., 2015, 54, 8684-8687.

10 W. Wang and V. Sprenkle, Nat. Chem., 2016, 8, 204-206.

11 M. L. Perry and A. Z. Weber, J. Electrochem. Soc., 2015, 163, A5064-A5067.

12 J. A. Suttil, J. F. Kucharyson, I. L. Escalante-Garcia, P. J. Cabrera, B. R. James, R. F. Savinell, M. S. Sanford and L. T. Thompson, J. Mater. Chem. A, 2015, 3, 7929-7938.

13 X. Xing, Y. Zhao and Y. Li, J. Power Sources, 2015, 293, 778783.

14 X. Xing, D. Zhang and Y. Li, J. Power Sources, 2015, 279, 205209.

15 D. Zhang, Q. Liu, X. Shi and Y. Li, J. Power Sources, 2012, 203, 201-205.

16 J. Winsberg, T. Hagemann, T. Janoschka, M. D. Hager and U. S. Schubert, Angew. Chem., Int. Ed. Engl., 2017, 56, 686711.

17 J. A. Kowalski, L. Su, J. D. Milshtein and F. R. Brushett, Curr. Opin. Chem. Eng., 2016, 13, 45-52.

18 N. G. Tsierkezos, J. Solution Chem., 2007, 36, 1301-1310.

19 X. Q. Xing, Y. J. Huo, X. Wang, Y. C. Zhao and Y. D. Li, Int. J. Hydrogen Energy, 2017, 42, 17488-17494.
20 J. Huang, L. Cheng, R. S. Assary, P. Wang, Z. Xue, A. K. Burrell, L. A. Curtiss and L. Zhang, Adv. Energy Mater., 2015, 5, 1401782.

21 J. Huang, L. Su, J. A. Kowalski, J. L. Barton, M. Ferrandon, A. K. Burrell, F. R. Brushett and L. Zhang, J. Mater. Chem. A, 2015, 3, 14971-14976.

22 J. Chen, C. Buhrmester and J. R. Dahn, Electrochem. SolidState Lett., 2005, 8, A59-A62.

23 F. R. Brushett, J. T. Vaughey and A. N. Jansen, Adv. Energy Mater., 2012, 2, 1390-1396.

24 S. Creager, in Handbook of Electrochemistry, Elsevier, Amsterdam, 2007, ch. 3, pp. 57-72.

25 A. A. Shinkle, T. J. Pomaville, A. E. S. Sleightholme, L. T. Thompson and C. W. Monroe, J. Power Sources, 2014, 248, 1299-1305.

26 T. Herr, J. Noack, P. Fischer and J. Tübke, Electrochim. Acta, 2013, 113, 127-133.

27 T. Herr, P. Fischer, J. Tübke, K. Pinkwart and P. Elsner, J. Power Sources, 2014, 265, 317-324.

28 M. O. Bamgbopa, N. Pour, Y. Shao-Horn and S. Almheiri, Electrochim. Acta, 2017, 223, 115-123.

29 S. V. Dzyuba and R. A. Bartsch, J. Heterocycl. Chem., 2001, 38, 265-268.

30 K. Wedege, E. Drazevic, D. Konya and A. Bentien, Sci. Rep., 2016, 6, 39101.

31 A. J. Bard and L. R. Faulkner, Electrochemical methods: fundamentals and applications, Wiley, New York, 2001.

32 J. Catalan, in Handbook of Solvents, ChemTec Publishing, 2nd edn, 2014, ch. 2, pp. 581-622.

33 A. Jouyban, S. H. Maljaei, S. Soltanpour and M. A. A. Fakhree, J. Mol. Liq., 2011, 162, 50-68. 